\title{
Development of Synbiotics with Inulin, Palatinose, a-Cyclodextrin and Probiotic Bacteria
}

\author{
RAMINTA PRANCKUTE்*, ARNOLDAS KAUNIETIS, NOMEDA KUISIENE் \\ and DONALDAS ČITAVIČIUS \\ Department of Microbiology and Biotechnology, Vilnius University, LT-03100, Vilnius, Lithuania
}

Submitted 20 June 2013, revised 20 October 2013, accepted 16 November 2013

\begin{abstract}
Success in creating a synbiotic depends on compatibility between the chosen components - prebiotic and probiotic. In this work the interactions between Lactobacillus sp. strains isolated from yogurts and type strains of Lactobacillus sp. and Lactococcus sp., and the dependence of their growth and antibacterial activity on three oligosaccharides (OS) - palatinose, inulin and a-cyclodextrin were investigated. All isolated lactobacilli produce antibacterial compounds, which possibly are the bacteriocins of Lactobacillus casei ATCC334 strain. Results of growth analysis with different OS revealed that part of lactobacilli isolated from yogurts can effectively ferment inulin and may be used for the development of synbiotics. Palatinose and Lactobacillus acidophilus could be used as symbiotics with effective antibacterial activity. One of the types of Lactococcus sp. strains can assimilate palatinose and a-cyclodextrin, so they both can be used as components of synbiotics with the investigated lactococci. Results of this analysis suggest that the investigated isolated and type strains of Lactobacillus sp. and Lactoccocus sp. can be useful as probiotics in the development of synbiotics. Together with prebiotics - palatinose, inulin and a-cyclodextrin, the synbiotics, which could regulate not only the growth of beneficial bacteria in the gastrointestinal tract, but also their antibacterial activity, can be created.
\end{abstract}

Ke y wo rd s: Lactobacillus sp., Lactococcus sp., bacteriocin, probiotic, synbiotic

\section{Introduction}

Synbiotic is a combination of probiotic and prebiotic, which can synergistically promote the growth of beneficial bacteria or newly added species in the colon (Macfarlane et al., 2008). During the development of new synbiotic products it is very important to ascertain prebiotic and probiotic interactions and influence of prebiotic on probiotic growth and antibacterial activity. Prebiotics are described as non-digestible poly-or oligosaccharides that beneficially affect the host by selectively stimulating the growth and/or activity of one or a limited number of beneficial bacteria in the colon (Gibson and Roberfroid, 1995). Prebiotics themselves have many health promoting properties. Moreover, there is evidence that they can help modulate the growth of gut microbiota and stimulate bacteriocin production (Kunova et al., 2011; Patel and Goyal, 2012).

Inulin, palatinose and $\alpha$-cyclodextrin used in this work are generally recognized as safe (GRAS) food additives (Wagner et al., 2008; Holub et al., 2010). Inulin is one of the most comprehensively studied OS and is widely recognized as a bifidogenic prebiotic (Bosscher et al., 2006; Patel and Goyal, 2012). Inulin is a liner polymer consisting of $\beta$ - $(2 \rightarrow 1)$-fructosyl-fructose linkages (Roberfroid, 2007). Palatinose is a reducing sugar, composed of glucose and fructose moieties, joined with $a-1,6$-glycozil bonds. Commercially palatinose is made from sucrose by enzymatically reorganizing glycosyl bonds (Holub et al., 2010). Cyclodextrins (CDs) are circular oligosaccharides, composed of glucose residues linked by $\alpha-1,4$-glycosyl bonds. The hydrophilic part of the molecule is faced to the outside of the ring, and the hydrophobic part is inside the ring (del Valle, 2004; Wagner et al., 2008). Commercially cyclodextrins are produced from a starch. These molecules are widely used in pharmacy, chemistry and food industry due to their ability to form inclusion complexes (del Valle, 2004). Although $\beta C D$ is more industrially used due to its lower price, $\alpha \mathrm{CD}$ is characterized by better solubility in water $(140 \mathrm{mg} / \mathrm{ml})$ than $\beta \mathrm{CD}\left(18 \mathrm{mg} / \mathrm{ml}, 25^{\circ} \mathrm{C}\right)$ (Szejtli, 2004).

Inulin, palatinose and $\alpha$-cyclodextrin can act in many health promoting ways, like stimulating immune system, reducing the amounts of pathogenic (Bacillus sp., Escherichia coli, Campylobacter jejuni, Salmonella

* Corresponding author: R. Pranckute, Department of Microbiology and Biotechnology, Vilnius University, M.K. Čiurlionio str. 21/27, Vilnius, Lithuania, LT-03100; phone: +37052398210; e-mail: raminta18@gmail.com 
enteritidis (Bosscher et al., 2006; Zhang et al., 2008)) or oral plaque bacteria (Porphyromonas gingivalis (Ueno et al., 2012)); reducing the risk of colon cancer; reducing triglycerides, fatty acids and cholesterol amounts in the blood and thus preventing cardiovascular diseases and decreasing the risk of obesity and type II diabetes (Wagner etal., 2008; Ooi and Liong, 2010; Patel and Goyal, 2012). Although these OS also have sweetness due to their indigestibility they are characterized by low glycaemic index (for example, palatinose has about half the sweetness of sucrose, but its glycaemic index is only 32 (Holub et al., 2010)). This makes them even more favorable food additives for diabetic patients.

Like most prebiotics, inulin, palatinose and $\alpha$-cyclodextrin are not digested in the upper gastrointestinal tract (except palatinose), which makes them available and longer lasting carbon sources for beneficial colon bacteria, like bifidobacteria (Bosscher et al., 2006; Goderska et al., 2008) and lactobacilli (Kunova et al., 2011). However, most investigations are focused on the influence of these OS on bifidobacteria and little is known about how they affect lactobacilli and other beneficial bacteria from other genera, like lactococci, widely used in the food industry (Pan et al., 2008; Gänzle and Follador, 2012). Most of them produce various antibacterially active compounds and bacteriocins among them (Chen et al., 2006). Not much research is done in this area, but there is evidence that bacteriocins may have various effects on the gut microbiota, like facilitating the introduction of the producing strain into the gastrointestinal tract, inhibiting the invasion of competing and pathogenic strains, modulating the composition of the gut microbiota and influencing the host immune system (Dobson et al., 2012). While bacteriocin production is often growthassociated and is dependent on carbon availability, slow digestion of prebiotics is very important as they are much longer-lasting carbon sources and mostly fermented only in the colon (Macfarlane et al., 2008). In addition to this, it is important to clarify the effect of prebiotics on the growth and antibacterial activity of probiotic bacteria (Chen et al., 2006). It is shown that inulin stimulates the secretion of bacteriocins by Lactobacillus paracasei CMGB16 strain (Vamanu and Vamanu, 2010). However, little is known about the influence of $\mathrm{aCD}$ and palatinose on probiotic bacteria, but it has been shown that $\mathrm{\alpha CD}$ can maintain the growth of Lactobacillus casei and increase the amounts of bifidobacteria (Jo et al., 2007). The analysis of L. casei supragenome has revealed that the bacterial strains of this species should be able to ferment inulin, palatinose and many other OS (Broadbent et al., 2012), which could be useful parts of synbiotics for diabetic patients. However, not many investigations of these properties have been made in vitro.

\section{Experimental}

Materials and Methods

Strain isolation from yogurts. The sources of Lactic Acid Bacteria (LAB) were probiotic yogurts: "Actimel" and "Bifi". For the isolation of strains, $1 \mathrm{~g}$ of each yogurt were added to $99 \mathrm{ml}$ of $0.85 \%$ sterile saline solution. Tenfold serial dilutions of the samples were made and appropriate dilutions were streaked on de Man, Ragosa and Sharpe (MRS) agar plates (Kormin et al., 2001). The plates were incubated for two days under anaerobic conditions at $37^{\circ} \mathrm{C}$ by placing a gas pack in the anaerobic jar (Merck).

Bacterial strains and growth conditions. Six Lactobacillus sp. and two Lactococcus sp. type strains were obtained from the German Collection of Microorganisms and Cell Cultures (DSMZ): Lactobacillus acidophilus DSM 20079 (LA), Lactobacillus delbrueckii subsp. bulgaricus DSM 20081 (LD), Lactobacillus curvatus DSM 20010 (LC), Lactobacillus sakei subsp. sakei DSM 20017(LS), Lactococcus lactis subsp. lactis DSM 20481 (LL) and L. lactis subsp. lactis DSM 20729 (LL2) (abbreviations of strains used further in the work are given in the brackets). Isolated and type strains of Lactobacillus sp. were cultured in MRS broth (Merck) or basal MRS (Saminathan et al., 2010). Type strains of Lactococcus sp. were grown in broth No. 92 (DSMZ culture medium list), which consisted of Tryptic Soy Broth (TSB, Merck), supplemented with $0.3 \%$ Yeast Extract (YE, Difco). Isolated strains were cultured aerobically or anaerobically, with $(100 \mathrm{rpm})$ or without agitation, at $30^{\circ} \mathrm{C}$. Type strains of L.acidophillus and L. delbrueckii subsp. bulgaricus were grown under anaerobic conditions, at $37^{\circ} \mathrm{C}$. Other type strains were cultured aerobically, at $30^{\circ} \mathrm{C}$.

Oligosaccharide substrates. Three different commercially available oligosaccharides were used in this study: inulin (Inl) (Alfa Aesar), palatinose hydrate (Pal) (TCI) and $\alpha$-cyclodextrin (Ctd, $\alpha \mathrm{CD}$ ) (Merck). Stock solutions of these oligosaccharides were prepared in sterile distilled water and filter sterilized with $0.22 \mu \mathrm{m}$ filters (Roth). The sterile oligosaccharide solutions were added to autoclaved basal MRS medium to obtain final oligosaccharide concentration of $1 \%(\mathrm{w} / \mathrm{v})$. Glucose (Merck), which was a favourable carbohydrate source for all used LAB strains, was used as control (Saminathan et al., 2010).

Partial identification of isolated strains. Genomic DNA of isolated strains was extracted using GeneJet DNA Extraction Kit (Thermo Fisher Scientific). Universal bacterial $16 \mathrm{~S}$ rDNA primers $(27 \mathrm{~F}$ and $1492 \mathrm{R}$, Thermo Fisher Scientific) were used for PCR reactions. Reaction products were sequenced at the Sequencing Center of the Institute of Biotechnology. In silico data analysis was performed using the NCBI Blast programme (http://blast.ncbi.nlm.nih.gov/Blast.cgi). 
In order to determine the variety of strains isolated from yogurts, we performed PCR reaction with all strains genomic DNA and universal BOX primers. Results were analyzed by agarose gel electrophoresis (Sambrook and Russell, 2001).

Antibacterial activity assay. The antibacterial activity of strains was determined using the spot-on-lawn method (Kormin et al., 2001) with modifications. The tested strain was grown overnight in the middle of Petri dish with an appropriate agar medium. Then the layer of agar medium with inoculated other presumably sensitive strain was poured on top of the grown culture. The agar media with inoculated strain was prepared by adding $20 \%$ of 1.2 OD culture inoculum into an appropriate agar media. Isolated and type strains were tested against each other.

Agar well diffusion assay. $0.5 \mathrm{~cm}$ diameter wells were made, using sterile plastic pipette tips, in the agar media with inoculated sensitive strain, prepared as described above. Culture samples were taken every two hours from the beginning of culture cultivation in liquid media. Samples were centrifuged and the serial twofold dilutions of the cell free supernatants were made. The amount of $100 \mu \mathrm{l}$ of every dilution was poured into the prepared wells and plates were incubated overnight at the temperature appropriate for the used indicator strain. Clear zones round the wells after incubation indicate the inhibitory activity, which was expressed quantitatively as arbitrary units per milliliter $(\mathrm{AU} / \mathrm{ml})$. The arbitrary unit (AU) was defined as the reciprocal of the highest dilution able to produce a clear zone of growth inhibition of the indicator strain (Vera Pingitore et al., 2007).

Disintegration of cells. Samples $(5 \mathrm{ml})$ of the grown cultures were taken every $6 \mathrm{~h}$ from the beginning of growth. Samples were centrifuged, cells were suspended in $5 \mathrm{ml}$ of phosphate buffer ( $\mathrm{pH}$ 6.0) and then disrupted with the ultrasound disintegrator. Obtained cell disintegrate was filtered through $0.22 \mu \mathrm{m}$ filter (Roth) or centrifuged (5 min, $14000 \times \mathrm{g}$ ). In order to determine the antibacterial activity, $100 \mu \mathrm{l}$ of the filtered, centrifuged and untreated disintegrates were tested using agar welldiffusion assay using A20 strain as indicator.

Identification of bacteriocins. Primers (20 pairs in total) used in this work were described in scientific publications or constructed using typical well known bacteriocin encoding gene sequences from the Genbank database (http://www.ncbi.nlm.nih.gov/Genbank/ index.html), are listed in Table I.

\section{Results}

Isolation of bacteria from yogurts. Since the morphology of bacteria grown on the MRS medium did not have any differences, 9 strains of Lactobacillus sp. iso- lates were randomly selected: 4 strains from "Actimel" yogurt ("Danone") (A isolates) and 4 from "Bifi" yogurt (UAB "Rokiškio pienas") (B isolates). The amount of Lactobacillus sp. bacteria in examined yogurts was estimated at $10^{8}$ cells in 1 gram of yogurt. These data coincide with the information given by the producers.

For a more detailed identification of the isolates $16 \mathrm{~S}$ rDNA analysis was made. Results have shown that the isolated strains are most similar to L.casei and L. paracasei subsp. tolerans species (reliability of BLAST analysis results is 100\%). Implementation of BOX-PCR reaction, used to estimate the variety of bacterial strains among isolates, has revealed distribution of strains in the profiles, fully complying with strains origin from different yogurts (data not shown).

Antagonistic activity assay of isolated strains. 3 strains from group A and 3 strains from group B were selected for the antagonistic activity assay. Using spoton-lawn method it was determined that all isolated lactobacilli strains were able to produce clear zones inhibiting the growth of the strains, used as indicator (isolated strains were tested against each other). Results, given in Table II, reflect the antagonistic spectrum of the tested strains. The obtained results allow us to assert that stains belonging to groups A and B produce antibacterially active compounds. The size of the formed clear zones (Table II.) shows that the antibacterial compound of B group strains is more active or a larger amount of it is produced.

Antibacterial activity of isolated and type strains. Antibacterial activity of 3 isolated (A11, B13, A20) and 6 type strains against each other was determined and phenotypically evaluated (Table III.). Results have shown that LL2 strain possesses the highest antibacterial activity among type strains. The antibacterial spectrum and ability to inhibit the growth of tested strains of this strain did not differ from antibacterial spectrum and activity of isolated lactobacilli strains A11, A20 and B13. However, only LD strain had no antibacterial activity against any of the tested strains and was sensitive to all antibacterial compounds secreted by the tested strains.

Identification of bacteriocins produced by isolated and type strains. One of the possibilities to identify secreted bacteriocins is a search of bacteriocin encoding genes in the genomes of analyzed strains. For this purpose we used 20 pairs of primers constructed in accordance with genes of well known bacteriocins (GeneBank Database) or selected from scientific publications (Table I.). All primers were used for PCR reactions with genomic DNA of 15 strains (9 isolated and 6 type strains). The results of the size and sequence analysis of the obtained PCR products can be divided into five groups: 1) Two PCR products compatible with genes encoding nisin by their size and results of 
Table I

Primers used for bacteriocin genes identification in studied bacterial strains.

\begin{tabular}{|c|c|c|c|c|c|}
\hline No & $\begin{array}{c}\text { Primer } \\
\text { (abbrevation) }\end{array}$ & Sequence & $\begin{array}{l}\mathrm{Tm}, \\
{ }^{\circ} \mathrm{C}\end{array}$ & $\begin{array}{l}\text { Expected product } \\
\text { (size, bp) }\end{array}$ & Source \\
\hline 1 & 1BACTP (1) & $\begin{array}{l}\text { F: 5'-TGA AGA TGT ATT TGG GTG CGT-3' } \\
\text { R: 5'-CAG GAG TTG CTG GTG TTG TT-3' }\end{array}$ & $\begin{array}{l}57 \\
58\end{array}$ & Lakticin 3147 (257) & $\begin{array}{l}\text { (Digaitiene } \\
\text { et al., 2012) }\end{array}$ \\
\hline 2 & 2BACTP (2) & $\begin{array}{l}\text { F: 5'-GCG CCT GCA GGG CTT TCT TTC GAT CAC GAT-3' } \\
\text { R: 5'-GCG CGT CGA CGG TTC GAT AGT TCG TGC TT-3' }\end{array}$ & $\begin{array}{l}75 \\
75\end{array}$ & Pediocin PA (541) & $\begin{array}{l}\text { (Digaitiene } \\
\text { et al., 2012) }\end{array}$ \\
\hline 3 & 3ВАCТP (3) & $\begin{array}{l}\text { F: 5’-CTA TGT ACA CCC GGT TGT AA-3' } \\
\text { R: 5'-TTT ATG AAC TAG GCG AAT CA-3' }\end{array}$ & $\begin{array}{l}56 \\
52\end{array}$ & Nizin (590) & $\begin{array}{l}\text { (Digaitiene } \\
\text { et al., 2012) }\end{array}$ \\
\hline 4 & 4BACTP (4) & $\begin{array}{l}\text { F: 5'-ACA GGT GGA AAA TAT TAT GGT A-3' } \\
\text { R: 5'-TTT TGC TTA TTA TTT ATT CCA G-3' }\end{array}$ & 55 & Sakacin P (150) & $\begin{array}{l}\text { (Digaitiene } \\
\text { et al., 2012) }\end{array}$ \\
\hline 5 & $\begin{array}{l}\text { BACTA164- } \\
\text {-NIZLL (A) }\end{array}$ & $\begin{array}{l}\text { F: 5'-ATG AGT ACA AAG ATT TTA ACT TGG ATT GGT-3' } \\
\text { R: 5'-ATA AAC GAA TGC ACT TAT GAT GTT ACT GT-3' }\end{array}$ & $\begin{array}{l}64 \\
63\end{array}$ & Nizin & $\begin{array}{l}\text { (Swetwiwathana } \\
\text { et al., 2009) }\end{array}$ \\
\hline 6 & $\begin{array}{l}\text { BACTWNC- } \\
\text {-NIZLL (W) }\end{array}$ & $\begin{array}{l}\text { F: 5'-CCG GAA TTC ATA AGG AGG CAC TCA AAA TG-3' } \\
\text { R: 5'-CGG GGT ACC TAC TAT CCT TTG ATT TGG TT-3' }\end{array}$ & $\begin{array}{l}69 \\
69\end{array}$ & Nizin A & $\begin{array}{l}\text { (Millette } \\
\text { et al., 2008) }\end{array}$ \\
\hline 7 & LacS (L) & $\begin{array}{l}\text { F: 5'-ATG GAA TTR TTR CCR ACK GCY GCY GTY YTR TA-3' } \\
\text { R: 5'-ATG RTG TTT RGC NSW RTA YTT-3' }\end{array}$ & $\begin{array}{l}72 \\
54 \\
\end{array}$ & Lakticin S & $\begin{array}{l}\text { (Rodrígues } \\
\text { et al., 1995) }\end{array}$ \\
\hline 8 & $\mathrm{~m} 2163(63)$ & $\begin{array}{l}\text { F: 5'-AAA CAT ATG AAA CGA AAG TGC CCC AAA AC-3' } \\
\text { R: 5'-TTT GAA TTC GCG ACG ATC TCT TGA ACA TTC-3' }\end{array}$ & $\begin{array}{l}66 \\
68\end{array}$ & $\begin{array}{l}\text { Class II bacteriocin } \\
(\leq 300)\end{array}$ & $\begin{array}{l}\text { (Kuo Y.-C. } \\
\text { et al., 2012) }\end{array}$ \\
\hline 9 & m2386 (86) & $\begin{array}{l}\text { F: 5'-ATT CAT ATG GAC AGC ATC CGT GAT GTT TC-3' } \\
\text { R: 5'-TTT GAA TTC GCT GCC AGA ACA AGT TGG TT-3' }\end{array}$ & $\begin{array}{l}68 \\
68\end{array}$ & $\begin{array}{l}\text { Class II bacteriocin } \\
(\leq 300)\end{array}$ & $\begin{array}{l}\text { (Kuo Y.-C. } \\
\text { et al., 2012) }\end{array}$ \\
\hline 10 & m2393 (93) & $\begin{array}{l}\text { F: 5'-GCT CAT ATG GAA AAC GGT GGT TTA TGG TCA-3' } \\
\text { R: 5’-AAA GAA TTC GGA ATC CCA GAA TGG CAG C-3' }\end{array}$ & $\begin{array}{l}69 \\
69 \\
\end{array}$ & $\begin{array}{l}\text { Class II bacteriocin } \\
(\leq 300)\end{array}$ & $\begin{array}{l}\text { (Kuo Y.-C. } \\
\text { et al., 2012) }\end{array}$ \\
\hline 11 & $\mathrm{~m} 2405$ (5) & $\begin{array}{l}\text { F: 5'-CAA CAT ATG GCC AAG CGA CGC-3' } \\
\text { R: 5'-CGA GAA TTC CGC TAC TAT TTC CC-3' }\end{array}$ & $\begin{array}{l}63 \\
63\end{array}$ & $\begin{array}{l}\text { Class II bacteriocin } \\
(\leq 300)\end{array}$ & $\begin{array}{l}\text { (Kuo Y.-C. } \\
\text { et al., 2012) }\end{array}$ \\
\hline 12 & $\mathrm{~m} 2406(6)$ & $\begin{array}{l}\text { F: 5'-TCA CAT ATG AAA AAG AAA TTT GAT TGT GCT-3' } \\
\text { R: 5'-TAA GAA TTC GCC CAC TTC TTT AC-3' }\end{array}$ & $\begin{array}{l}63 \\
59\end{array}$ & $\begin{array}{l}\text { Class II bacteriocin } \\
(\leq 300)\end{array}$ & $\begin{array}{l}\text { (Kuo Y.-C. } \\
\text { et al., 2012) }\end{array}$ \\
\hline 13 & AcdT (AT) & $\begin{array}{l}\text { F: 5'-ATG ATT TCA TCT CAT CAA AAA ACG-3' } \\
\text { R: 5'-CTA AAAACC GTC AGT ATA ACG AAG GC-3' }\end{array}$ & $\begin{array}{l}57 \\
65\end{array}$ & $\begin{array}{l}\text { Acidocin } 8120 \\
(141)\end{array}$ & This work \\
\hline 14 & CurA (CA) & $\begin{array}{l}\text { F: 5'-GCG CAG GAA TGA TTT CTG TAG GC-3' } \\
\text { R: 5’-GCT CTG CCT TCA AAT TAG ACC CTC-3' }\end{array}$ & $\begin{array}{l}65 \\
65\end{array}$ & Curvacin A (179) & This work \\
\hline 15 & CurA2 (CA2) & $\begin{array}{l}\text { F: 5'-GCG CAG GAA TGA TTT CTG TAG GC-3' } \\
\text { R: 5'-TGG GAT CAT TTG GCG TCT GC-3' }\end{array}$ & $\begin{array}{l}65 \\
60 \\
\end{array}$ & $\begin{array}{l}\text { Curvacin A and } \\
\text { imunity gene (837) }\end{array}$ & This work \\
\hline 16 & SakA (SA) & $\begin{array}{l}\text { F: 5'-GCG CAG AGG AGA TTC TTA GTT ATG-3' } \\
\text { R: 5'-CAT TCC AGC TAA ACC ACT AGC CC-3' }\end{array}$ & $\begin{array}{l}64 \\
65\end{array}$ & Sakacin A (197) & This work \\
\hline 17 & SakP (SP) & $\begin{array}{l}\text { F: 5'-GCA GAA GTA ACA GCA ATT ACA GGT GG-3' } \\
\text { R: 5'-CGC TAG CGT ATT CTT AGA ATA GTG TGC-3' }\end{array}$ & $\begin{array}{l}66 \\
67\end{array}$ & Sakacin P (622) & This work \\
\hline 18 & 92 & $\begin{array}{l}\text { F: 5'-ATG AAA AAA CAA GAA ACA CAA TTG TTT GAA GC-3' } \\
\text { R: 5'-TCA TCT AAA AAT CTG AGT CAA TCC CC-3' }\end{array}$ & $\begin{array}{l}65 \\
63\end{array}$ & $\begin{array}{l}\text { Prebakteriocin } \\
(186)\end{array}$ & This work \\
\hline 19 & 94 & $\begin{array}{l}\text { F: 5'-TTG GGT GGA AAG GAA ACA CGG TTA TTT CAG GC-3' } \\
\text { R: 5'-TCA AAG CCA AAC GCT CAA CCC GCC-3' }\end{array}$ & $\begin{array}{l}72 \\
69\end{array}$ & $\begin{array}{l}\text { Prebakteriocin } \\
(192)\end{array}$ & This work \\
\hline 20 & 111 & $\begin{array}{l}\text { F: 5’-ATG ACA GAC AAA CGT GAAACT TTA ATG TCG-3' } \\
\text { R: 5'-GTA ATG CCC CCA AAC AAT GGG AAT GG-3' }\end{array}$ & $\begin{array}{l}67 \\
68\end{array}$ & $\begin{array}{l}\text { Prebakteriocin } \\
(333)\end{array}$ & This work \\
\hline
\end{tabular}

BLAST analysis (primers 3 and $\mathrm{W}$, genomic DNAs of LL2 and LL strains respectively, Table I). 2) PCR products, obtained with 5 primers constructed for detection of new bacteriocins of L. casei ATCC334 (63, 86, 93, 405, 406) (Kuo et al., 2013) and genomic DNAs of isolated strains. Sequences of the products had homo- logy with the sequences of new bacteriocins, mentioned before. 3) PCR products obtained with primers constructed according to prebacteriocin genes found in the genome of L. casei BDII strain (Genbank Database, GI: 385821700) (primers 92, 94 and 111 (Table I.), genomic DNAs of isolated strains), which were compatible with 
Table II

Results of antibacterial spectrum of isolated strains.

\begin{tabular}{|c|c|c|c|c|c|c|c|}
\hline & \multicolumn{6}{|c|}{ Sensitive strain } \\
\hline & & A11 & A15 & A20 & B1 & B4 & B13 \\
\hline \multirow{6}{*}{  } & A11 & & + & ++ & + & + & + \\
\hline & A15 & + & & ++ & + & + & + \\
\hline & A20 & + & + & & + & + & + \\
\hline & B1 & ++ & ++ & +++ & & ++ & ++ \\
\hline & B4 & ++ & ++ & +++ & + & & + \\
\hline & B13 & +++ & +++ & +++ & ++ & ++ & \\
\hline
\end{tabular}

"+" - diameter of the clear zone arround the secreting culture exeeds $1.5 \mathrm{~mm}$; "++" - clear zone $\leq 2.5 \mathrm{~mm}$, “+++" - zone $>2.5 \mathrm{~mm}$.

Table III

Results of antibacterial activity of isolated and type strains.

\begin{tabular}{|c|c|c|c|c|c|c|c|c|c|c|}
\hline & \multicolumn{9}{|c|}{ Sensitive strain } \\
\hline & & A11 & B13 & A20 & LA & LD & LL & LL2 & LC & LS \\
\hline \multirow{9}{*}{ 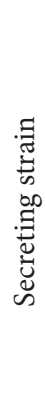 } & A11 & & + & ++ & + & +++ & +++ & +++ & ++ & ++ \\
\hline & B13 & +++ & & +++ & + & +++ & +++ & +++ & ++ & ++ \\
\hline & A20 & + & + & & ++ & +++ & +++ & +++ & ++ & ++ \\
\hline & LA & $+/-$ & $+1-$ & $+1-$ & & ++ & + & + & $+/-$ & + \\
\hline & LD & - & - & - & - & & - & - & - & - \\
\hline & LL & $+/--$ & $+/--$ & $+/--$ & $+1--$ & + & & + & + & + \\
\hline & LL2 & ++ & + & ++ & + & +++ & ++ & & +++ & +++ \\
\hline & LC & - & $+/-$ & $+1-$ & $+1-$ & ++ & + & + & & + \\
\hline & LS & + & $+/-$ & + & $+1-$ & + & + & + & + & \\
\hline
\end{tabular}

"+/--" - clear zone is visible only by the borders of the secreting culture "+/-" - clear zone is hardly visible, $\leq 0.5 \mathrm{~mm}$; "+" - clear zone $\leq 1.5 \mathrm{~mm}$; "++" - clear zone $\leq 2.5 \mathrm{~mm}$, "+++" - clear zone $>2.5 \mathrm{~mm}$.

the prebacteriocin genes by their size and sequence. However, more detailed in silico analysis of these products, using Bactibase database (http://bactibase. pfba-lab-tun.org/physicochem), has shown that, most likely, these genes do not encode bacteriocins. 4) PCR products, obtained with primers for well known bacteriocin genes and genomic DNAs of isolated and some of the type strains (primer for nisin (3) with genomic DNA of isolated, LL and LA strains; primer for lacticin 3147 (1) with genomic DNA of isolated and LD strains; primer for curvacin A (CA2) with genomic DNA of isolated and LD strains), which were not compatible with these bacteriocin genes by their size and sequence analysis, but were identified as hypothetical or unrelated function proteins. 5) No PCR products were obtained with 7 primers for the well known bacteriocin genes (pediocin PA (2), sakacin P (4 and SP), sakacin A (SA), lacticin S (L), acidocin 8120 (AT), curvacin A (CA) (Table I)) and genomic DNAs of all strains.

Ability of the isolated and type strains to assimilate OS. Considering the results of BLAST and BOXPCR analysis, only strains A11 and B13 were used for further experiments, as they represent different groups of BOX-PCR profiles and possess the highest antibacterial activity among the strains of their groups (Table II.).

Data from the graphs presented in Fig. 1. (A and B) suggest that in all cases both A11 and B13 strains most weakly assimilate palatinose hydrate. On the other hand, inulin is poorly assimilated only by strain A11 (Fig. 1A). The growth of strain B13 with inulin is equivalent to the growth of this strain with glucose, except that the exponential growth phase begins about $4 \mathrm{~h}$ later (Fig. 1B). The increase of OS concentration does not influence the growth of strains.

Analysing the influence of different carbon sources (glucose, inulin and palatinose) on the type strains of Lactobacillus sp. and Lactococcus sp., the following was determined:

1. In the medium with glucose as an only carbon source L. lactis subsp. lactis strains (LL and LL2) grew faster than strains LS and LA. LL and LL2 strains reached the stationary phase after 6 and $8 \mathrm{~h}$ respectively (Fig. 1C and D), while strains LS and LA reached this phase of growth after 14 and $28 \mathrm{~h}$ respectively (Fig. 1E and F). Evaluation of growth time and cell density at the beginning of the stationary phase suggests that strain LL2 grows fastest in the medium with glucose.

2. Strain LL assimilates palatinose best among the type strains (Fig. 1C). The culture reaches cell density of $1.2 \mathrm{OD}$ in the beginning of stationary phase after $14 \mathrm{~h}$ of growth, while assimilation of inulin is ineffective - maximum reached OD was 0.5.

3. The assimilation of inulin and palatinose by strain LS is completely ineffective (Fig. 1E).

4. Strain LL2 equally poorly assimilates both inulin and palatinose. Only $0.5 \mathrm{OD}$ cell density is reached in the beginning of the stationary phase, after $5 \mathrm{~h}$ of growth (Fig. 1D)

5. LA also ineffectively assimilates inulin and palatinose. The stationary phase with the cell density of $0.5 \mathrm{OD}$ is reached after $12 \mathrm{~h}$ in the medium with inulin and only after $24 \mathrm{~h}$ when growing with palatinose (0.45 OD) (Fig. 1F).

The MRSb medium becomes opaque after addition of $\alpha \mathrm{CD}$ and it becomes impossible to track the alterations of OD. Therefore, the influence $a C D$ on the growth of strains was analysed only with strains LL and LL2. Results (Fig. 1C and D) have shown that $a C D$ is actively assimilated by LL2 strain.

Evaluation of antibacterial activity of isolated strains. Antibacterial activity of culture supernatants was evaluated by the well-diffusion method during the growth (Vera Pingitore et al., 2007). Strain A20 was used as indicator for the evaluation antibacterial activity of the isolated strains, while testing on agard medium by spot-on-lawn method it demonstrated the highest 

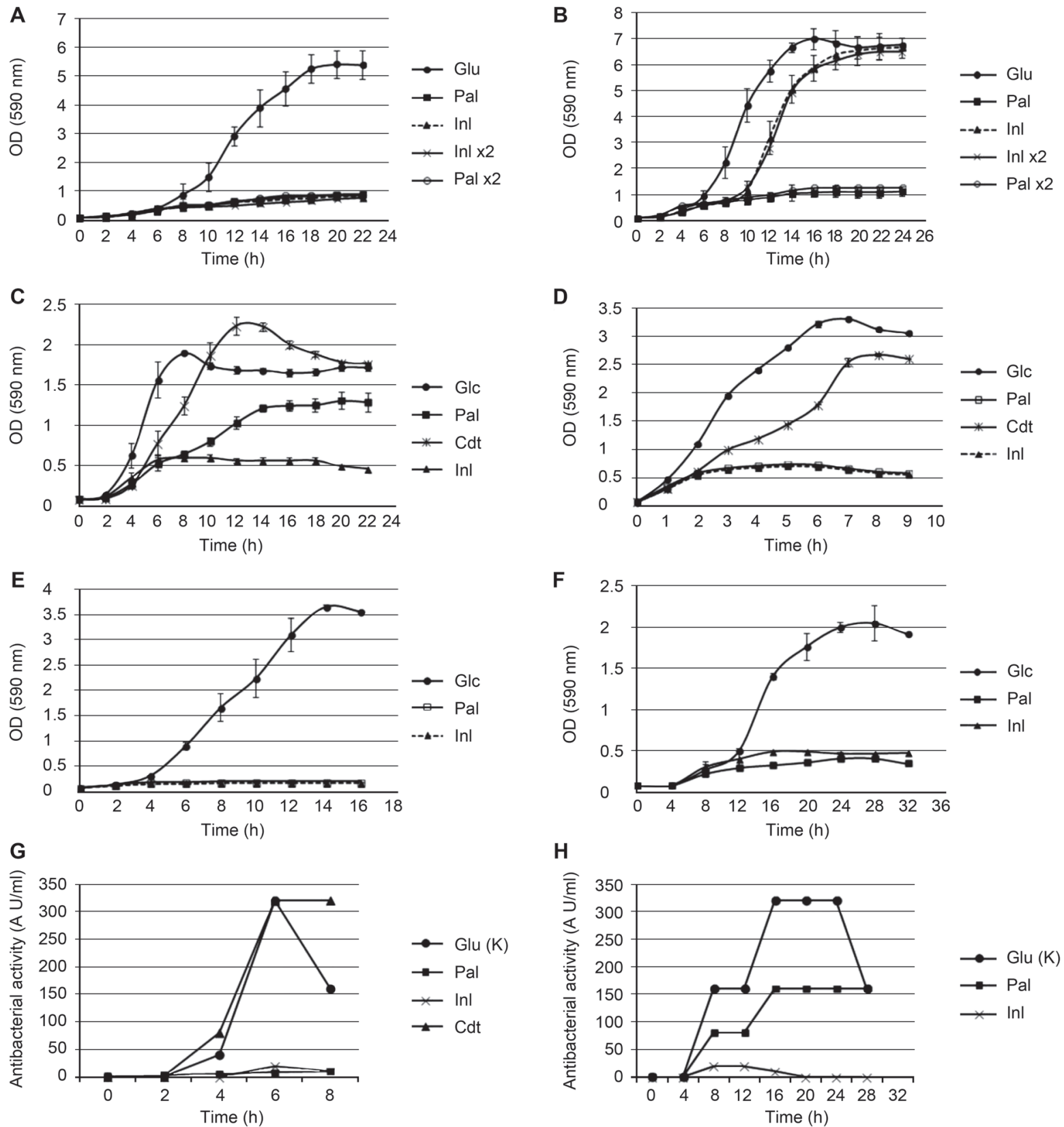

Fig. 1. OS influence on the growth and antibacterial activity of isolated and type strains of Lactobacillus sp. and Lactococcus sp. Curves are marked with abbreviations of used OS: Glu - glucose; Pal - palatinose; Inl - inulin; Cdt - a-cyclodextrin. Concentration of OS $-1 \%, \times 2-2 \%(\mathrm{w} / \mathrm{v})$. A - OS influence on the growth of A11 strain. B - OS influence on the growth of B13 strain. C - OS influence on the growth of L. lactis subsp. lactis (LL) strain. D - OS influence on the growth of L. lactis subsp. lactis (LL2) strain. E - OS influence on the growth of L. sakei subsp. sakei (LS) strain. F-OS influence on the growth of L.acidophilus (LA) strain. G - OS influence on the antibacterial activity of L. lactis subsp. lactis (LL2) strain. H - OS influence on the L. acidophilus (LA) strain.

sensitivity to the antibacterial compounds secreted by other isolated strains (Table II). However, no antibacterial activity was detected while testing supernatants from the cultures grown in the liquid medium. The negative results could be caused by:

- interaction between antibacterial compound and cell surface;

- accumulation of antibacterial compound inside the cell;

- low concentration of the secreted antibacterial compound.
Accordingly, the cultivation of strains A11 and B13 was repeated after addition of $0.5 \%$ and $1 \%$ of Tween- 80 , which should reduce the interaction between proteins and cell surface and also enlarge the amount of antibacterial compound in the culture supernatant (the initial concentration of Tween- 80 in the MRS medium is $0.1 \%)$. However, no clear zones were detected after repeated evaluation of antibacterial activity of culture supernatants.

Culture samples $(5 \mathrm{ml})$ were taken every 6 hours from the beginning of growth. The samples were centri- 
fuged and cells were disintegrated. Antibacterial activity of filtered, centrifuged and untreated cell disintegrates was tested by the well-diffusion assay, but no antibacterial activity was detected.

Aiming to increase the amount of antibacterial compound, A11 and B13 strains were grown in the liquid medium till the end of exponential growth phase. $50 \mathrm{ml}$ of every culture supernatants were salted out with $80 \%$ saturation of ammonium sulphate. Suspension of proteins was dialyzed in the phosphate buffer and concentrated up to $2 \mathrm{ml}$ of volume. The antibacterial activity of the crude protein extracts was tested by the well-diffusion method, but no definite clear zones were detected.

Another factor that could influence the production of bacteriocins is a deficiency of certain minerals. So strains A11 and B13 were grown in medium supplemented with combination of minerals, which were optimized in our laboratory to the growth and bacteriocin production of bacteria from other genera. It was shown that addition of $\mathrm{NaHSO}_{4}$ and $\mathrm{MnSO}_{4}$ to the medium $\left(\mathrm{MnSO}_{4}\right.$ is an ingredient of $\mathrm{MRSb}$ medium) almost completely inhibits the growth of strain A11, but in the case of strain B13, these minerals only prolong the lag phase of growth. Other used combinations of minerals practically have no influence on the growth of the strains. However, culture supernatants did not possess any antibacterial activity either.

It is known that $\mathrm{pH}$ of the growth medium strongly influences to the bacteriocin expression. But no antibacterial activity in culture supernatants after changing the $\mathrm{pH}$ of the growth medium from 5.6 to 7.2 was detected.

OS influence on bacteriocin secretion. Strain A20 was replaced with LL as indicator strain (Table III.) and the antibacterial activity of A11 and B13 culture supernatants repeatedly grown with different carbon sources (glucose or 1\% OS) was evaluated by welldiffusion assay. In this case about $2 \mathrm{~mm}$ of diameter unclear transparency zones around the wells with the culture supernatants after 12 and $14 \mathrm{~h}$ of growth were detected. The activity of secreted putative bacteriocins was minor - after diluting the supernatants only two times the activity was not detected. LL2, LS, LD and LC strains were also used as indicators but no clear zones had been detected around the wells with A11 and B13 strains grown in liquid medium culture supernatants either.

No antibacterial activity was detected in culture supernatants while analyzing the influence of OS on the type strains, although all type strains, sensitive to the grown strains respectively (Table III.), were used as sensitive. Positive results were obtained only with strains LL2 and LA while using LS and LC strains as indicators.

The antibacterial activity of strain LL2 culture supernatants was tested using LC strain as indicator, as it is characterized by the highest sensitivity to the bacteriocin secreted by LL2 strain (Table III). After $6 \mathrm{~h}$ of growth of this strain in the medium with glucose or $\alpha$-cyclodextrin, the antibacterial activity of culture supernatants was two times higher $(80 \mathrm{AU} / \mathrm{ml})$ when grown with $\alpha \mathrm{CD}$, than with glucose $(40 \mathrm{AU} / \mathrm{ml})$, although the cell density of the culture grown with glucose at that moment was almost two times bigger, than grown with aCD (1.5 OD and $0.8 \mathrm{OD}$ respectively) (Fig. 1G). These results show that $\mathrm{aCD}$ positively influences bacteriocin production or activity. While growing the strain in the medium with inulin or palatinose, the antibacterial activity was detected only after $8 \mathrm{~h}(20 \mathrm{AU} / \mathrm{ml})$. That suggests that strain LL2 is not capable of assimilating palatinose and inulin and, therefore, the antibacterial activity of culture supernatants is very weak (Fig. 1G). It should be noted that culture supernatant, obtained after $10 \mathrm{~h}$ of growth with aCD, maintains the same activity as after 8 h of growth $(320 \mathrm{AU} / \mathrm{ml})$, and while growing in the medium with glucose, the activity of culture supernatant decreases two times (Fig. 1G).

Strain LS is characterized by high sensitivity to the antibacterial compound produced by strain LA (Table III). Due to this fact, this strain was used as indicator for evaluation of the antibacterial activity of strain LA grown in the liquid medium. Besides, both these strains can be cultivated in the MRS medium. Diverse influence of OS on the antibacterial activity of LA strain, grown with different carbon sources - glucose, palatinose and inulin was shown (Fig. 1H). During the growth of this strain, the antibacterial activity of culture supernatant occurred in the 8th hour of growth. Culture supernatants of 16, 20 and 24 hours possessed the highest activity $(320 \mathrm{AU} / \mathrm{ml})$ during the exponential growth phase of the investigated strain. Cell density of the LA culture after $8 \mathrm{~h}$ of growth in the medium with glucose or with palatinose practically does not differ. Although the antibacterial activity of the culture supernatant with palatinose is two times lower, the activities becomes equal after $28 \mathrm{~h}$ of growth, when the culture ends the exponential growth in the medium with glucose and is already in the stationary phase in the medium with palatinose (Fig. $1 \mathrm{~F}$ and $\mathrm{H}$ ). The cell density of the culture is equal (0.5 OD) after $12 \mathrm{~h}$ of growth in the medium with glucose and in the medium with inulin, but the antibacterial activity of the culture supernatant with inulin is 8 times lower. The antibacterial activity decreases two times after $16 \mathrm{~h}$ of growth in the medium with inulin and becomes undetectible after $20 \mathrm{~h}$.

It should be noted that the growth of the LA strain measuring the cell density of the cultures in the media with inulin and palatinose only slightly differs (1.25 times) (Fig. 1F). However, the antibacterial 
activity of culture supernatants with palatinose at those hours, when it is possible to evaluate the antibacterial activity of the supernatants with inulin, is at least 8 times higher (Fig. 1H).

\section{Discussion}

Three oligosaccharides were used in this work: palatinose and inulin, characterized by low caloricity and prebiotic properties, and a-cyclodextrin - practically not investigated as a component of synbiotics. The possibility to use these prebiotics in the development of synbiotics for healthy and especially for diabetic people, may be an effective mean for enhancement of the immune system and prevention of colon infections by pathogenic microorganizms.

Probiotics are the second component of synbiotics. One of the ways by which probiotics may influence proliferation of pathogenic bacteria in the gastrointestinal tract are bacteriocins, secreted by them. In this work, it has been demonstrated that Lactobacillus sp. strains, isolated from "Activia" and "Bifi" yogurts, are bacteriocin producers. In solid medium clear transparent zones, indicating growth inhibition of the sensitive strain, independently of whether glucose or OS were used as an only carbon source, were obtained. However, no antibacterial activity was detected in the liquid media. According to the literature, there was shown, that in many cases LAB strains exhibits antibacterial activity on solid but not in liquid media. However, further investigations showed that most of these bacteriocins could be produced also in liquid media, but only under optimized conditions (MaldonadoBarragán et al., 2009). We did not succeed to obtain crude extracts of these bacteriocins, although all methodical procedures usual for bacteriocin extraction were carried out. However, the obtained PCR products suggests that they may be the newly characterized bacteriocins of L. casei ATCC 334 (Kuo et al., 2013). Furthermore, analysis results of the ability to ferment the used carbon sources and influence of microelements on the growth of A11 and B13 strains confirm the distribution of isolated lactobacilli strains into two physiological groups, compatible with BOX-PCR profiles and isolation sources. These results suggest that $\mathrm{B}$ group lactobacilli have specific genetic systems enabling them to ferment inulin. However, palatinose is not assimilated by strains belonging to both $\mathrm{A}$ and $\mathrm{B}$ groups.

In the case of two type L. lactis and two type Lactobacillus strains it was determined that in the growth media with different $O S$ as an only carbon source L. lactis subsp. lactis strains demonstrated good fermentation of a-cyclodextrin, almost equal to that of glucose. However, Lactococcus sp. strains differ in the efficiency of palatinose assimilation - LL stands out of all tested strains for the ability to ferment palatinose. It shows that this strain has specific enzymes, required for the transport and hydrolysis of this disaccharide.

LS strain is totally unable to assimilate inulin and palatinose. On the other hand, LA strain ferments these OS inefficiently. Analysis of the influence of glucose, palatinose, inulin and $\alpha$-cyclodextrin on the bacteriocin expression of LL and LL2 strains shows that in the case of glucose and $a$-cyclodextrin bacteriocins appear in the medium in the late stationary phase, which suggests that these antibacterial substances, according to PCR results - possibly nisin, are released into the growth medium during the lysis of cells.

The analysis of isolated lactobacilli in the medium with inulin as an only carbon source show that this OS can be used as a prebiotic to create synbiotics with $B$ group lactobacilli isolated from yogurts. According to the analysis of L. casei genomes, carried out by Broadbent and coworkers (2012), members of this species are able to ferment inulin. This and the results of $16 \mathrm{~S} \mathrm{rDNA}$ analysis suggest that our isolated strain B13 belongs to the L. casei species. Palatinose and LA strain could be used as synbiotics with the effective antibacterial activity. The same property would be characteristic of a synbiotic based on $a$-cyclodextrin and strain LL2.

The presented results offer the possibility to create synbiotics on the basis of probiotics - Lactobacillus sp. and Lactococcus sp. and prebiotics - palatinose, inulin and $\alpha$-cyclodextrin, which could regulate not only the growth of different lactobacilli and lactococci, but also the efficiency of their antibacterial activity.

\section{Acknowledgements \\ This work was supported by the "ThermozymOS" project (Grant No. SVE-08/2011) of the Research Council of Lithuania.}

\section{Literature}

Bosscher D., J. Van Loo and A. Franck. 2006. Inulin and ologofructose as prebiotics in the prevention of intestinal infections and diseases. Nutr. Res. Rev. 19(2): 216-26.

Broadbent J.R., E.C. Neeno-Eckwall, B. Stahl, K. Tandee, H. Cai, W. Morovic, P. Horvath, J. Heidenreich, N.T. Perna, R. Barrangou and J.L. Steele. 2012. Analysis of the Lactobacillus casei supragenome and its influence in species evolution and lifestyle adaptation. BCM Genomics 13: 533.

Chen Y.-S., S. Srionnual, T. Onda and F. Yanagida. 2007. Effects of prebiotic oligosaccharides and trehalose on growth and production of bacteriocins by lactic acid bateria. Lett. Appl. Microbiol. 45: 190-193.

Digaitiene A., Å.S. Hansen, G. Juodeikiene, D. Eidukonyte and J. Josephsen. 2012. Lactic acid bacteria isolated from rye sourdoughs produce bacteriocin-like inhibitory substances active against Bacillus subtilis and fungi. J. Appl. Microbiol. 112: 732-742.

Dobson A., P.D. Cotter, R.P. Ross and C. Hill. 2012. Bacteriocin Production: a Probiotic Trait? Appl. Environ. Microb. 78(1): 1-6. 
Gänzle M.G. and R. Fallador. 2012. Metabolism of oligosaccharides and starch in lactobacilli: a review. Food Microbiol. 340(3): 1-15. Gibson G.R. and M.B. Roberfroid. 1995. Dietary modulation of the human colonic microbiota: introducing the concept of prebiotics. J. Nutr. 125: 1401-1412.

Goderska K., J. Nowak and Z. Czarnecki. 2008. Comparison of the growth of Lactobacillus acidophilus and Bifidobacterium bifidum species in media supplemented with selected saccharides including prebiotics. Acta Sci. Pol. 7(2): 5-20.

Holub I., A. Gostner, S. Theis, L. Nosek, T. Kudlich, R. Melcher and W. Scheppach. 2010. Novel findings of the metabolic effects of the low glycaemic carbohydrate isomaltulose (Palatinose ${ }^{\mathrm{TM}}$ ). Brit. J. Nutr. 103: 1730-1737.

Jo A., D. Nakata, K. Terao, M. Otani and K. Sano. 2007. New Synbiotics by the combination of $\alpha$-cyclodextrin and lactic acid bacteria, Proceedings of $25^{\text {th }}$ Cyclodextrin Symposium in Japan Tottori, Japan. p. 144-145.

Kormin S., G. Rusul, S. Radu and F.H. Ling. 2001. Bacteriocinproducing lactic acid bacteria isolated from traditional fermented food. Malays. J. Med. Sci. 8(1): 63-68.

Kunová G., V. Rada, I. Lisová, Š. Ročková and E. Vilková. 2011. In vitro Fermentability of Prebiotic Oligosaccharides by Lactobacilli. Czech. J. Food Sci. 29(Special Issue): 49-54.

Kuo Y.-C., C.-F. Liu, J.-F. Lin, A.-C. Li, T.-C. Lo and T.-H. Lin. 2013. Characterisation of putative class II bacteriocins identified from a non-bacteriocin-producing strain Lactobacillus casei ATCC 334. Appl. Microbiol. Biotechnol. 97(1): 237-246.

Macfarlane G.T., H. Steed and S. Macfarlane. 2008. Bacterial metabolism and health-related effects of galacto-oligosaccharides and other prebiotics. J. Appl. Microbiol. 104: 305-344.

Maldonado-Barragán A., J.L. Ruiz-Barba and R. Jiménez-Díaz. 2009. Knockout of three-component regulatory systems reveals that the apparently constitutive plantaricin-production phenotype shown by Lactobacillus plantarum on solid medium is regulated via quorum sensing. Int. J. Food Microbiol. 130(1): 35-42.

Millette M., G. Carnut, C. Dupont, F. Shareck, D. Archambault and M. Lacroix. 2008. Capacity of Human Nisin-and PediocinProducing Lactic Acid Bacteria To reduce Intestinal Colonization by Vancomycin-Resistant Enterococci. Appl. Environ. Microbiol. 74(7): 1997-2003.

Ooi L.-G. and M.-T. Liong. 2010. Cholesterol-Lowering Effects of Probiotics and Prebiotics: A Review of in Vivo and in Vitro Findings. Int. J. Mol. Sci. 11: 2499-2522.

Pan X., T. Wu, L. Zhang, L. Cai and Z. Song. 2009. Influence of oligosaccharides on the growth and tolerance capacity of lactobacilli to simulated stress environment. Lett. Appl. Microbiol. 48: 362-367. Patel S. and A. Goyal. 2012. The current trends and future perspectives of prebiotics research: a review. 3 Biotech 2: 115-125.

Roberfroid M.B. 2007. Inulin-Type Fructans: Functional Food Ingredients. J. Nutr. 137: 2493S-2502S.

Rodríguez J.M., L.M. Cintas, P. Casaus, A. Suárez and P.E. Hernández. 1995. PCR Detection of the Lactocin S Structural Gene in Bacteriocin-Producing Lactobacilli from Meat. Appl. Environ. Microbiol. 61(7): 2802-2805.

Sambrook J. and D.W. Russell. 2001. Molecular cloning; a laboratory manual. $3 r d$ ed. Cold Spring Harbor, NY: Cold Spring Harbor Laboratory.

Saminathan M., C.C. Sieo, R. Kalavathy, N. Abdullah and Y.W. Ho. 2010. Effect of prebiotic oligosaccharides on growth of Lactobacillus strains used as probiotic for chickens. Afr. J. Microbiol. Res. 5(1): 57-64.

Swetwiwathana A., T. Zendo, J. Nakayama and K. Sonomoto. 2009. Identification of Nisin Z producing Lactococcus lactis N12 associated with traditional Thai fermented rice noodle (Kanom Jien). As. J. Food. Ag-Ind. 2(02): 116-125.

Szejtli J. 2004. Past, present and future of cyclodextrin research. Pure Appl. Chem. 76(10): 1825-1845.

Ueno C., A. Jo, D. Nakata, K. Terao, M. Otani, K. Sano, T. Oshima and N. Naeda. 2012. Enhacement of Antibacterial Activity of Manuka Honey on Periodontal Pathogenic Bacteria with a-Cyclodextrin, Proceedings of $29^{\text {th }}$ Cyclodextrin Symposium. Hoshi univ., Tokyo, Japan. p. 198-199.

del Valle E.M.M. 2004. Cyclodextrins and their uses: a review, Process Biochem. 39(9): 1033-1046.

Vamanu E. and A. Vamanu. 2010. The influence of prebiotics on bacteriocin synthesis using the strain Lactobacillus paracasei CMGB16. Afr. J. Microbiol. Res. 4(7): 534-537.

Vera Pingitore E., E. Salvucci, F. Sesma and M.E. Nader-Macías. 2007. Different strategies for purification of antimicrobial peptides from Lactic Acid Bacteria (LAB), p. 557-568. In: Mendez-Vilas A. (Ed.). Communicating Current Research and Education Topics and Trends in Applied Microbiology. Microbiology Series n 1, Vol. 2. Formatex, Spain.

Wagner E.M., K.-L.C. Jen, J.D. Artiss and A.T. Remaley. 2008. Dietary alpha-cyclodextrin lowers LDL-C and alters plasma fatty acid profile in LDLr-KO mice on a high-fat diet. Metabolism 57(8): 1046-1051.

Zhang H.-M., Z. Li, K. Uematsu, T. Kobayashi and K. Horikoshi. 2008. Antibacterial activity of cyclodextrins against Bacillus strains. Arch. Microbiol. 190: 605-609. 
